\title{
La Ley 8/2013, de 26 de junio, de rehabilitación, regeneración y renovación urbanas
}

Juan-Cruz Alli Aranguren

\begin{abstract}
Sumario: I. Objeto.-II. Afección normativa._III. Introducción sobre los motivos de la ley.-IV. Título preliminar.-V. Título I. El informe de evaluación de los edificios (IEE).—VI. Título II. Las actuaciones sobre el medio urbano. VI.1. Actuaciones y sujetos obligados. VI.2. Ordenación y gestión. VI.3. Fórmulas de cooperación y coordinación para participar en la ejecución.-VII. Disposiciones adicionales. VII.1. Sistema informativo general. VII.2. Sistema informativo catastral. VII.3. Infracciones y sanciones en materia de certificación de la eficiencia energética de los edificios.VIII. Disposiciones transitorias. VIII.1. Calendario para la realización del informe de evaluación de los edificios (Dt 1. a). VIII.2. Regla temporal de aplicación excepcional de la reserva mínima de suelo para vivienda protegida (Dt 2. ${ }^{a}$ ).-IX. Modificaciones normativas introducidas por las disposiciones finales. IX.1. Modificaciones de mayor relieve. IX.2. La disposición final 12. ${ }^{a}$ y la ley de suelo.-X. Conclusión.
\end{abstract}

El título de la Ley $8 / 2013$, de 26 de junio, de rehabilitación, regeneración y renovación urbanas (1), ya conocida como "LRRRU», promueve este tipo de actuaciones desde una concepción sostenible del medio urbano, ya invocada por la Ley 8/2007, a la que ahora se añade la del fomento de la actividad económica y la calidad ambiental de los edificios en cuanto al cambio climático.

Sin embargo, como se apreciará, su amplio contenido afecta a numerosos aspectos, entre ellos a los del régimen del suelo, regulados por la Ley 8/2007, de 28 de mayo, y por su Texto Refundido publicado por el Real Decreto Legislativo 2/2008, de 20 de junio. Aunque el esquema lo hace de toda la Ley, se destacan las innovaciones sobre esta última norma, que se recogen en su Título II sobre las "actuaciones en el medio urbano", que es donde se hallan las edificaciones que han de ser objeto de las políticas para su rehabilitación, regeneración y renovación. Ya que se trata del suelo urbano, aprovecha para introducir otras reformas sobre el mismo que no tienen relación con las anteriores.

(1) Publicada en el Boletín Oficial del Estado 153, de 27 de junio de 2013. Entró en vigor el 28 de junio de 2013. 


\section{Objeto}

El artículo 1 regular las condiciones básicas que garanticen un desarrollo sostenible, competitivo y eficiente del medio urbano, mediante el impulso y el fomento de las actuaciones que conduzcan a la

- rehabilitación de los edificios,

- regeneración y renovación de los tejidos urbanos existentes, cuando sean necesarias para asegurar a los ciudadanos una adecuada calidad de vida y la efectividad de su derecho a disfrutar de una vivienda digna y adecuada (art. $47 \mathrm{CE}$ ).

Como recoge la Exposición de motivos, cuantificando la importancia del parque edificado, tanto residencial como turístico, hay en estos procesos un potencial económico y de trabajo, necesarios en el actual momento económico. Así lo entiende la Ley cuando invoca como uno de los títulos competenciales el relativo a la planificación general de la actividad económica (art. 149.1.13. ${ }^{a}$ CE), que le permite fijar un "común denominador normativo" con margen para la actuación de las Comunidades Autónomas y los Municipios.

La Ley supera la concepción sobre la rehabilitación referida exclusivamente a las edificaciones aisladas, para introducir la "regeneración y renovación urbanas», que se podrán realizar por medio de instrumentos de planeamiento, en continuidad con las figuras históricas de la "renovación y reforma interior de poblaciones» y de los "planes especiales de reforma interior" (art. 12 LS 1956). Así lo confirma el artículo 7.1 sobre el objeto de las actuaciones al prever la «regeneración y renovación urbanas, cuando afecten [...] a tejidos urbanos, pudiendo llegar a incluir obras de nueva edificación en sustitución de edificios previamente demolidos». En el mismo sentido el artículo 10.1 cuando se refiere a "alterar la ordenación urbanística vigente», a los "programas u otros instrumentos de ordenación» y a la delimitación del ámbito. Entra en el propio de la competencia urbanística de las Comunidades Autónomas establecer los instrumentos de planeamiento adecuados a tales fines.

Aunque la Ley no lo recoge de modo explicito, implícitamente considera que se trata de una función pública directiva que, lo mismo que la urbanística, cuenta con los particulares en las varias situaciones en que participan (2). La experiencia ha demostrado que no es suficiente la adopción de medidas de policía, como las "órdenes» de ejecución» o la "ruina», sino que es precisa una acción más decidida que abarque desde la planificación hasta la sustitución del tejido urbano, del mismo modo que se ha venido realizando en la ocupación del exterior de la ciudad.

A todo ello se une la búsqueda de mecanismos que pretenden conseguir que la financiación para la rehabilitación sea más accesible y se encuentre al alcance de los interesados. Se establecen además, otros mecanismos específicos para facilitar la financiación de estas actuaciones, entre los que destacan los convenios entre las Administraciones Públicas actuantes, los propietarios y demás sujetos que vayan a intervenir en la ejecución.

(2) Así se desprende de la modificación por la DF 12. ‥3.1. del artículo 6 TRLS: "1. Los particulares, sean o no propietarios, deberán contribuir, en los términos establecidos en las leyes, a la acción urbanística de los entes públicos, a los que corresponderá, en todo caso, la dirección del proceso, tanto en los supuestos de iniciativa pública como privada». 


\section{Afección normativa}

Una vez más, el legislador ha aprovechado una ley y, con mayor o menor relación con su contenido material, ha introducido otras reformas (3). Son muchas las normas directamente afectadas por la Ley 8/2013, de 26 de junio, como se recoge en sus Disposiciones Finales, según su orden:

— Ley 49/1960, de 21 de julio, sobre Propiedad Horizontal (DF 1. ${ }^{\text {a)} .}$

- Ley 13/1998, de 4 de mayo, de Ordenación del Mercado de Tabacos y Normativa Tributaria (DF 2. ${ }^{a}$ ).

- Ley 38/1999, de 5 de noviembre, de Ordenación de la Edificación (DF 3. ${ }^{a}$ ).

- Ley 1/2000, de 7 de enero, de Enjuiciamiento Civil (DF 4. ${ }^{\text {a) }}$.

- Ley 21/2003, de 7 de julio, de Seguridad Aérea (DF 5. ${ }^{a}$ ).

- Ley 33/2003, de 3 de noviembre, del Patrimonio de las Administraciones Públicas (DF 6. $\left.{ }^{a}\right)$.

- Ley 38/2003, de 17 de noviembre, General de Subvenciones (DF 7. ${ }^{\text {a) }}$.

- Ley 47/2003, de 26 de noviembre, General Presupuestaria (DF 8. ${ }^{a}$ ).

- Ley 58/2003, de 17 de diciembre, General Tributaria (DF 9. ${ }^{\text {) }}$.

- Real Decreto Legislativo 2/2004, de 5 de marzo, Ley Reguladora de las Haciendas Locales (DF 10. ${ }^{\text {a). }}$

— Real Decreto 314/2006, de 17 de marzo, por el que se aprueba el Código Técnico de la Edificación (DF 11.a).

- Real Decreto Legislativo 2/2008, de 20 de junio, Texto Refundido de la Ley de Suelo (DF 12. ${ }^{\text {) }}$.

- Real Decreto Legislativo 3/2011, de 14 de noviembre, Texto refundido de la Ley de Contratos del Sector Público (DF 13. ${ }^{\circ}$ ).

- Real Decreto-Ley 6/2012, de 9 de marzo, de medidas urgentes de protección de deudores hipotecarios sin recursos (DF 14. ${ }^{\text {a) }}$.

— Ley 9/2012, de 14 de noviembre, de reestructuración y resolución de entidades de crédito (DF 15. ${ }^{2}$ ).

- Ley 17/2012, de 27 de octubre, de Presupuestos Generales del Estado para el año 2013 (DF 16. ${ }^{\text {a) }}$

- Ley 1/2013, de 14 de mayo, de medidas para reforzar la protección a los deudores hipotecarios, reestructuración de la deuda y alquiler social (DF 17. ${ }^{\text {a) }}$.

La disposición derogatoria contiene la cláusula general y la derogación explícita de los artículos de las Leyes citadas, subsumidos con una nueva redacción.

\section{Introducción sobre los motivos de la ley}

Como es propio de los preámbulos de las leyes, la 8/2013 expone los motivos y principios que la inspiran, lo que es más necesario cuando se trata de una norma de contenido complejo y heterogéneo. Es realmente extenso y está dividido en nueve

(3) Aunque con menor incidencia, recuerda a la Ley 25/2009, de 22 de diciembre, denominada Ley ómnibus, que modificó 47 leyes y 116 decretos-leyes y otras muchas disposiciones para implementar en España la Directivas 2006/123/CE, conocida como Directiva Bolkestein. 
partes, que se invocan en relación con la regulación de sus 19 artículos, 4 disposiciones adicionales, 2 transitorias, 1 derogatoria y 20 finales, que constituyen una importante modificación del ordenamiento jurídicos vigente, como se ha recogido en el epígrafe anterior.

Los cuatro primeros apartados del preámbulo exponen el diagnostico de la situación del mercado del suelo y de la vivienda en España en el actual momento de crisis económica, que ha contribuido a agravar los existentes con anterioridad.

a) Urbanismo disperso frente a urbanismo concentrado:

Invoca la Ley 8/2007, de 28 de mayo, de Suelo, que expuso cual había sido el modelo de crecimiento urbano propio de los periodos de desarrollismo y especulación inmobiliaria:

La tradición urbanística española, como ya reconoció el legislador estatal [...] se ha volcado fundamentalmente en la producción de nueva ciudad, descompensando el necesario equilibrio entre dichas actuaciones y aquellas otras que, orientadas hacia los tejidos urbanos existentes, permiten intervenir de manera inteligente en las ciudades, tratando de generar bienestar económico y social y garantizando la calidad de vida a sus habitantes.

b) Dificultades de la intervención sobre el interior de la ciudad y el patrimonio edificado, que se han incrementado con el cambio de ciclo económico:

Estas otras intervenciones son mucho más complejas, tanto desde el punto de vista social como económico; complejidad que se agrava en el momento presente a consecuencia de un contexto desfavorable para la financiación pública, debido a los procesos de estabilización presupuestaria, y también para la financiación privada, por las restricciones en el acceso a los créditos, derivadas de la crisis del sector financiero y del empobrecimiento de muchas familias a consecuencia de los altos niveles de desempleo.

c) Cambio de modo de actuar: del exterior al interior de la ciudad para lograr un modelo sostenible e integrador, por la rehabilitación, regeneración y renovación urbanas:

Sin embargo, el camino de la recuperación económica, mediante la reconversión del sector inmobiliario y de la construcción y también la garantía de un modelo sostenible e integrador, tanto ambiental, como social y económico, requieren volcar todos los esfuerzos en aquellas actuaciones, es decir, las de rehabilitación y de regeneración y renovación urbanas, que constituyen el objeto esencial de esta Ley.

d) Exceso de oferta de suelo exterior y de viviendas nuevas vacías:

Tal y como se deduce del Sistema de Información Urbana y el Estudio de Sectores Residenciales en España 2011, ambos elaborados por el Ministerio de Fomento, España posee actualmente, si no se reactiva la demanda, suelo capaz de acoger nuevos crecimientos urbanísticos para los próximos cuarenta y cinco años. Esta situación se 
agrava cuando se observa que gran parte de estos suelos se encuentran situados en entornos donde no es previsible ningún incremento de demanda en los próximos años. A ello se une el dato significativo de vivienda nueva vacía, 723.043 viviendas.

e) Este modelo tiene excedentes y un régimen normativo que difícilmente va a contribuir al crecimiento económico y a crear empleo:

Tanto a corto, como a medio plazo, será muy difícil que los sectores inmobiliario y de la construcción puedan contribuir al crecimiento de la economía española y a la generación de empleo si continúan basándose, principalmente y con carácter general, en la transformación urbanística de suelos vírgenes y en la construcción de vivienda nueva.

f) Sin embargo, la actuación hacia el interior por medio de la rehabilitación, regeneración y renovación urbanas carecen de un régimen adecuado, incluso existen obstáculos legales y falta de viabilidad técnica y económica:

Es preciso, por tanto, generar un marco normativo idóneo para dichas operaciones, que no sólo llene las lagunas legales actualmente existentes, sino que remueva los obstáculos que las imposibilitan en la práctica y que propicie la generación de ingresos propios para hacer frente a las mismas.

g) Se utilizan la rehabilitación y la regeneración y renovación urbanas como medio para la recuperación económica, coadyuvando a la reconversión de otros sectores, particularmente de uno tan importante para la economía española como es el turismo:

La actividad turística es clave para la economía de nuestro país y supone más de un 10,2 \% del PIB, aportando un 11,39 \% del empleo. Numerosos destinos turísticos «maduros» se enfrentan a un problema sistémico en el que tiene mucho que ver el deterioro físico de sus dotaciones y respecto de los cuales, la aplicación de estrategias de rehabilitación, regeneración y renovación urbanas podría generar impactos positivos que, a su vez, servirían de palanca imprescindible para el desarrollo económico de España.

En el apartado II del preámbulo se expone y justifica la necesidad de intervenciones de rehabilitación, regeneración y renovación para poder hacer efectivo el derecho constitucional a una vivienda digna y adecuada (art. $47 \mathrm{CE}$ ), y el deber de los propietarios de mantener los inmuebles en las adecuadas condiciones de conservación. Aproximadamente el $55 \%$ (13.759.266) de dicho parque edificado, que asciende a 25.208.622 viviendas, es anterior al año 1980 y casi el $21 \%(5.226 .133)$ cuentan con más de 50 años. Sin embargo existe un déficit normativo:

a) El único instrumento que actualmente permite determinar el grado de conservación de los inmuebles es la Inspección Técnica de Edificios:

no sólo es insuficiente para garantizar dicho objetivo, y así se pone de manifiesto desde los más diversos sectores relacionados con la 
edificación, sino que ni siquiera está establecido en todas las Comunidades Autónomas, ni se exige en todos los municipios españoles.

b) Inadecuación de la eficiencia energética de los edificios y, a través de ellos, de las ciudades, a las exigencias europeas recogidas en la norma básica de la edificación NBE-CT-79, sobre condiciones térmicas en los edificios (4):

La Unión Europea ha establecido una serie de objetivos en el «Paquete Verde» 20-20-20 "Energía y Cambio Climático», que establece, para los 27 países miembros, dos objetivos obligatorios: la reducción del $20 \%$ de las emisiones de gases de efecto invernadero y la elevación de la contribución de las energías renovables al 20 \% del consumo (5), junto a un objetivo indicativo, de mejorar la eficiencia energética en un $20 \%$.

c) Estos objetivos obligan a reducir las emisiones de gases de efecto invernadero del sector y a mejorar la eficiencia del conjunto del parque residencial, conforme a la Directiva 2012/27/UE, relativa a la eficiencia energética con una

estrategia a largo plazo, hasta el año 2020 —para minorar el nivel de emisiones de $\mathrm{CO}_{2}$ y hasta el año 2050 - con el compromiso de reducir el nivel de emisiones un 80-95 \% en relación a los niveles de 1990-, destinada a movilizar inversiones en la renovación de edificios residenciales y comerciales, para mejorar el rendimiento energético del conjunto del parque inmobiliario. A través de esta estrategia de renovaciones exhaustivas y rentables que reduzcan el consumo de energía de los edificios, en porcentajes significativos con respecto a los niveles anteriores a la renovación, se crearán además oportunidades de crecimiento y de empleo en el sector de la construcción.

d) Contribución a la sostenibilidad ambiental y a la cohesión social y a la mejora de la calidad de vida de todos los ciudadanos, tanto en las viviendas y en los edificios, como en los espacios urbanos:

No en vano, muchas de las más importantes operaciones de regeneración y renovación urbanas tienen, además, un carácter integrado, es decir, articulan medidas sociales, ambientales y económicas, que se suman a las estrictamente físicas para lograr, mediante una estrategia unitaria, la consecución de aquellos objetivos.

e) Integración de la actividad de rehabilitación en áreas que permitan aplicar políticas integrales

(4) Certificado de eficiencia energética exigida por la Directivas 2002/91/CE y 2010/31/UE, regulado por los Reales Decretos 235/2013, de 5 de abril, procedimiento básico para la certificación de la eficiencia energética de los edificios, y 238/2013, de 5 de abril, modificación de las del Real Decreto 1027/20007, de 20 de julio, Reglamento de Instalaciones térmicas de los edificios.

(5) Las expresadas medidas recibieron el refrendo del Consejo Europeo (8 y 9 de marzo de 2007) y se aprobaron las correspondientes Directivas del Parlamento y del Consejo en el año 2009, ratificando el triple objetivo 20-20-20 en el umbral del 2020. La Directiva 2009/28/CE, de 23 de abril, sobre fomento del uso de energía procedente de fuentes renovables, modificó y derogó las anteriores Directivas reguladoras (2001/77/CE y 2003/30/CE). 
que contemplen intervenciones no solo en el ámbito físico-espacial, sino también en los ámbitos social, económico, ambiental y de integración de la ciudad. El tamaño de estas operaciones permitirá la puesta en servicio de redes de instalaciones energéticas a escala de barrio, con menor consumo de recursos, y que permitirían que los barrios tiendan a la autosuficiencia energética en el medio plazo.

f) La consecución de un medio urbano sostenible es una exigencia comunitaria e internacional, que obliga al Estado a ejercitar sus competencias, sin perjuicio de las competencias de las Comunidades Autónomas en materia de vivienda y urbanismo:

La Directiva 2002/91/CE del Parlamento Europeo y del Consejo, de 16 de diciembre de 2002, refundida posteriormente en la Directiva 2010/31/ UE del Parlamento Europeo y del Consejo, de 19 de mayo de 2010, relativa a la eficiencia energética de los edificios y la Directiva 2012/27/UE del Parlamento Europeo y del Consejo, de 25 de octubre de 2012, relativa a la eficiencia energética, a las que pueden añadirse la Estrategia Temática para el Medio Ambiente Urbano, el Marco Europeo de Referencia para la Ciudad Sostenible, o la Declaración de Toledo —aprobada [...] el 22 de junio de 2010_, de acuerdo con la cual «la batalla principal de la sostenibilidad urbana se ha de jugar precisamente en la consecución de la máxima ecoeficiencia posible en los tejidos urbanos de la ciudad ya consolidada", y en la que se destaca la importancia de la regeneración urbana integrada y su potencial estratégico para un desarrollo urbano más inteligente, sostenible y socialmente inclusivo en Europa.

g) Es, además, una política adecuada en tiempos de crisis comprobada la inadecuación de la política de crecimiento externo expansivo de las ciudades, "tales como la generación de nueva ciudad y nuevas viviendas, sólo es posible actuando sobre el patrimonio inmobiliario y la edificación existente», con importantes exigencias y efectos económicos:

También se enmarca en la necesidad de operar, paralelamente, sobre el patrimonio inmobiliario existente a los efectos de contribuir al ahorro energético, con el relanzamiento de la industria de materiales, así como de la relativa a las restantes instalaciones y dotaciones de la edificación y de las tecnologías de energías renovables, para hacer frente, no sólo a los retos energéticos de la economía española — dependencia del exterior en energías primarias e incremento de costes y riesgos que tal dependencia supone-, sino también a los compromisos adquiridos en el contexto de la Unión Europea y su paquete de objetivos en materia energética y de lucha contra el cambio climático para el año 2020. Estos compromisos incluyen la intervención sobre el parque de viviendas existentes en cuanto sector en el que es posible un ahorro energético considerable y en el que hay que incidir también desde el punto de vista de la lucha contra el cambio climático, inducido por los gases de efecto invernadero.

h) Competencia básica estatal basada en los siguientes títulos: 
- establecer las bases y la coordinación de la planificación general de la actividad económica (art. 149.1.13. ${ }^{a} \mathrm{CE}$ ), que fija un "común denominador» de "carácter nuclear», que deja suficiente margen a las Comunidades Autónomas para el ejercicio de las competencias que les son propias, particularmente en cuanto a los instrumentos de planeamiento y gestión (6).

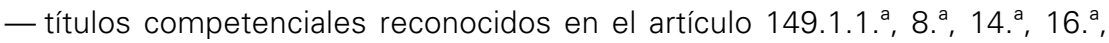
18. ${ }^{a}, 23{ }^{a}{ }^{a}, 25 .^{a}$ y $30 .^{a}$ CE sobre regulación de las condiciones básicas que garantizan la igualdad en el ejercicio de los derechos y en el cumplimiento de los deberes constitucionales, legislación civil, hacienda general y deuda del Estado, bases y coordinación general de la sanidad, bases del régimen jurídico de las Administraciones Públicas, procedimiento administrativo común, legislación sobre expropiación forzosa y el sistema de responsabilidad de las Administraciones Públicas, legislación básica sobre protección del medio ambiente, bases del régimen energético y regulación de las condiciones de obtención, expedición y homologación de títulos académicos y profesionales.

i) Objetivos perseguidos:

El apartado III del preámbulo expone los objetivos que concreta como mandato el artículo 1 de la Ley.

En primer lugar, potenciar la rehabilitación edificatoria y la regeneración y renovación urbanas, eliminando trabas actualmente existentes y creando mecanismos específicos que la hagan viable y posible.

En segundo lugar, ofrecer un marco normativo idóneo para permitir la reconversión y reactivación del sector de la construcción, encontrando nuevos ámbitos de actuación, en concreto, en la rehabilitación edificatoria y en la regeneración y renovación urbanas.

En tercer lugar, fomentar la calidad, la sostenibilidad y la competitividad, tanto en la edificación, como en el suelo, acercando nuestro marco normativo al marco europeo, sobre todo en relación con los objetivos de eficiencia, ahorro energético y lucha contra la pobreza energética.

Termina vinculándolo con los objetivos y mandatos comunitarios respecto a la eficiencia energética, atender a los desafíos del cambio climático y la transformación del modelo productivo

hacia parámetros de sostenibilidad ambiental, social y económica, con la creación de empleos vinculados con el medio ambiente, los llamados empleos verdes, en concreto, aquellos vinculados con las energías renovables y las políticas de rehabilitación y ahorro energético.

Para conseguirlos modifica numerosas normas para eliminar obstáculos que impiden alcanzar los objetivos propuestos y para adaptar los existentes a los nuevos.

(6) Se ha de citar como importante precedente de esta Ley la Ley $2 / 2013$, de 29 de mayo, de renovación y modernización turística de las Islas Canarias. Regula la modernización turística por medio de los planes generales y de otros planes de modernización con objeto de "viabilizar la renovación urbana y edificatoria». 


\section{Título preliminar}

Recoge los siguientes aspectos de la Ley:

- El artículo 1 describe su objeto, como se ha expuesto.

- El artículo 2 recoge las definiciones de los conceptos que utiliza en relación con la residencia habitual, la infravivienda(7), el coste de reposición, los ajustes razonables, los complejos inmobiliarios y la tipología residencial colectiva. Deja a salvo las definiciones más pormenorizadas de la legislación específica.

- El artículo 3 enumera los fines comunes de las políticas públicas para un medio urbano más sostenible, eficiente y competitivo. De modo que «los poderes públicos formularán y desarrollarán en el medio urbano las políticas de su respectiva competencia de acuerdo con los principios de sostenibilidad económica, social y medioambiental, cohesión territorial, eficiencia energética y complejidad funcional, para:

a) Posibilitar el uso residencial en viviendas constitutivas de domicilio habitual en un contexto urbano seguro, salubre, accesible universalmente, de calidad adecuada e integrado socialmente, provisto del equipamiento, los servicios, los materiales y productos que eliminen o, en todo caso, minimicen, por aplicación de la mejor tecnología disponible en el mercado a precio razonable, las emisiones contaminantes y de gases de efecto invernadero, el consumo de agua, energía y la producción de residuos, y mejoren su gestión.

b) Favorecer y fomentar la dinamización económica y social y la adaptación, la rehabilitación y la ocupación de las viviendas vacías o en desuso.

c) Mejorar la calidad y la funcionalidad de las dotaciones, infraestructuras y espacios públicos al servicio de todos los ciudadanos y fomentar unos servicios generales más eficientes económica y ambientalmente.

d) Favorecer, con las infraestructuras, dotaciones, equipamientos y servicios que sean precisos, la localización de actividades económicas generadoras de empleo estable, especialmente aquéllas que faciliten el desarrollo de la investigación científica y de nuevas tecnologías, mejorando los tejidos productivos, por medio de una gestión inteligente.

e) Garantizar el acceso universal de los ciudadanos a las infraestructuras, dotaciones, equipamientos y servicios, así como su movilidad.

f) Integrar en el tejido urbano cuantos usos resulten compatibles con la función residencial, para contribuir al equilibrio de las ciudades y de los núcleos residenciales, favoreciendo la diversidad de usos, la aproximación de los servicios, las dotaciones y los equipamientos a la comunidad residente, así como la cohesión y la integración social.

\footnotetext{
(7) Según el artículo 2.2. es infravivienda «la edificación, o parte de ella, destinada a vivienda, que no reúna las condiciones mínimas exigidas de conformidad con la legislación aplicable. En todo caso, se entenderá que no reúnen dichas condiciones las viviendas que incumplan los requisitos de superficie, número, dimensión y características de las piezas habitables, las que presenten deficiencias graves en sus dotaciones e instalaciones básicas y las que no cumplan los requisitos mínimos de seguridad, accesibilidad universal y habitabilidad exigibles a la edificación». Resulta conceptualmente contraria a la "vivienda digna y adecuada» que el artículo 47 CE declara como derecho a su disfrute, que se ha concretado como derecho subjetivo exigible por algunas Comunidades Autónomas.
} 
g) Fomentar la protección de la atmósfera y el uso de materiales, productos y tecnologías limpias que reduzcan las emisiones contaminantes y de gases de efecto invernadero del sector de la construcción, así como de materiales reutilizados y reciclados que contribuyan a mejorar la eficiencia en el uso de los recursos.

h) Priorizar las energías renovables frente a la utilización de fuentes de energía fósil y combatir la pobreza energética con medidas a favor de la eficiencia y el ahorro energético.

i) Valorar, en su caso, la perspectiva turística y permitir y mejorar el uso turístico responsable.

j) Favorecer la puesta en valor del patrimonio urbanizado y edificado con valor histórico o cultural.

k) Contribuir a un uso racional del agua, fomentando una cultura de eficiencia en el uso de los recursos hídricos, basada en el ahorro y en la reutilización.

\section{Título I. El informe de evaluación de los edificios (IEE)}

Integrado por tres artículos contiene la regulación básica del Informe de Evaluación de los Edificios (IEE), que parte de otra disposición heterogénea, el Real Decreto-ley 8/2011, de 1 de julio, de medidas de apoyo a los deudores hipotecarios, de control del gasto público y cancelación de deudas con empresas y autónomos contraídas por las entidades locales, de fomento de la actividad empresarial e impulso de la rehabilitación y de simplificación administrativa, superando algunas de sus insuficiencias.

Con este instrumento el legislador estatal trata de establecer el régimen para evaluar el estado de conservación de los edificios, sus condiciones de accesibilidad universal (8), y de eficiencia energética para

a) Asegurar la calidad y sostenibilidad del parque edificado, así como obtener información que le permita orientar el ejercicio de sus propias políticas. Su exigencia también se limita a aquellos edificios que tienen verdadera transcendencia en relación con los mencionados objetivos, así como con una determinada política económica y de vivienda a escala estatal, que son los de tipología colectiva y siempre que su uso sea el residencial o asimilado.

b) Facilitar a las Administraciones competentes un instrumento que les permita disponer de la información precisa para evaluar el cumplimiento de las condiciones básicas legalmente exigibles, tanto en materia de conservación, como de accesibilidad, reguladas por la Ley de Suelo, aprobado por el Real Decreto Legislativo 2/2008, de 20 de junio, y la Ley 26/2011, de 1 de agosto, de adaptación normativa a la Convención Internacional sobre los Derechos de las Personas con Discapacidad, que exige la realización de los ajustes razonables en materia de accesibilidad universal (con sus obras correspondientes), estableciendo incluso un plazo, que finaliza en el año 2015, momento a partir del cual

(8) Conforme a la Ley 26/2011, de 1 de agosto, de adaptación de la Convención Internacional sobre los derechos de las Personas con Discapacidad, que se realizarán hasta 2015, momento en que será legalmente exigibles. 
pueden ser legalmente exigidos, tanto para los edificios, como para los espacios públicos urbanizados existentes y, por tanto, controlados por la Administración Pública competente.

c) Valorar con carácter orientativo la eficiencia energética y el cumplimiento de los compromisos de España con Europa en el horizonte 2020: la Certificación de la Eficiencia Energética de los Edificios, exigida por la Directiva 2002/91/ CE del Parlamento Europeo y del Consejo, de 16 de diciembre, relativa a la eficiencia energética, y por la Directiva 2010/31/UE del Parlamento Europeo y del Consejo, de 19 de mayo de 2010, que la refunde y completa. Por medio de la calificación del edificio a tales efectos (mediante letras, de la A a la G), recomendaciones sobre las mejoras energéticas que podrían realizarse, analizadas en términos de coste/beneficio y clasificadas en función de su viabilidad técnica, económica y funcional y de su repercusión energética. Dado que la Directiva exige que esta certificación se adjunte cuando una vivienda se ponga en venta o en alquiler, en aras de una mayor transparencia del mercado, una mayor información para los propietarios y un menor coste en su emisión, se busca la doble racionalidad y sinergia que supone incluirla en el informe de evaluación del edificio.

El artículo 4 establece su régimen:

a) Administración requirente: Podrá ser la Comunidad Autónoma o el Municipio (arts. 4.1 y DT $1 .{ }^{a}$ ).

b) Sujetos obligados (art. 4.1):

Los propietarios de inmuebles ubicados en edificaciones con tipología residencial de vivienda colectiva podrán ser requeridos por la Administración competente para que acrediten la situación en la que se encuentran aquéllos, al menos en relación con el estado de conservación del edificio y con el cumplimiento de la normativa vigente sobre accesibilidad universal, así como sobre el grado de eficiencia energética de los mismos.

c) Plazos (DT 1.a):

- Los edificios de tipología residencial de vivienda colectiva con una antigüedad superior a 50 años, en el plazo máximo de cinco años, a contar desde la fecha en que alcancen dicha antigüedad, salvo que ya cuenten con una inspección técnica vigente, realizada de conformidad con su normativa aplicable y con anterioridad a la entrada en vigor de esta Ley. En este último caso, se exigirá el Informe de Evaluación cuando corresponda su primera revisión de acuerdo con aquella normativa, siempre que la misma no supere el plazo de diez años, a contar desde la entrada en vigor de esta Ley. Si así fuere, el Informe de Evaluación del Edificio deberá cumplimentarse con aquellos aspectos que estén ausentes de la inspección técnica realizada.

- Los edificios cuyos titulares pretendan acogerse a ayudas públicas con el objetivo de acometer obras de conservación, accesibilidad universal o eficiencia energética, con anterioridad a la formalización de la petición de la correspondiente ayuda. 
- El resto de los edificios, cuando así lo determine la normativa autonómica o municipal, que podrá establecer especialidades de aplicación del citado informe, en función de su ubicación, antigüedad, tipología o uso predominante.

d) Contenido del Informe:

Los requisitos del Informe los establece el apartado 2, con el alcance que se detalla en los apartados siguientes.

- El Informe de Evaluación realizado por encargo de la comunidad o agrupación de comunidades de propietarios extenderá su eficacia a todos y cada uno de los locales y viviendas existentes (art. 4.3).

- Tendrá una periodicidad mínima de diez años, pudiendo establecer las Comunidades Autónomas y los Ayuntamientos una periodicidad menor (art. 4.4).

- Si no se cumplimenta debidamente, se incurre en una infracción urbanística (art. 4.5).

- Los propietarios obligados deberán remitir una copia del mismo al organismo que determine la Comunidad Autónoma, con el fin de que dicha información forme parte de un Registro integrado único.

e) Coordinación:

Dispone el artículo 5 que para la coordinación administrativa, los Informes de Evaluación nutrirán los censos de construcciones, edificios, viviendas y locales que precisen rehabilitación.

Se dictan criterios para relacionarlo con el Informe de Evaluación de los Edificios del Real Decreto-ley 8/2011, de 1 de julio, para evitar duplicidades. Se debe de tener en cuenta que se derogan en el mismo:

- La disposición adicional tercera sobre la aplicación de la Inspección Técnica de Edificios obligatoria, a la que sustituye, integrándose en la ITE.

- Las disposiciones transitorias primera y segunda, sobre la eficacia de las inspecciones técnicas ya realizadas y el calendario para las inspecciones técnicas.

f) Competencia:

La capacitación para la emisión del Informe la regulan el artículo 6 y la DF 18. ${ }^{a}$, conforme a la cual la determinación de las cualificaciones que se requerirán para suscribir los Informes de Evaluación de Edificios (9) y el modo de acreditarlas será objeto de desarrollo reglamentario, mediante Orden Ministerial (DF 18. ${ }^{\text {) }}$.

\section{Título II. Las actuaciones sobre el medio urbano}

Este título contiene las actuaciones sobre el medio urbano en su enumeración (art. 7) identificando los sujetos obligados (art. 8). Respecto a las primeras ofrece nuevos instrumentos para facilitar la gestión y la cooperación interadministrativa tan necesaria en estos casos, diferenciando entre los de "ordenación y gestión» (arts. 9-14) y las fórmulas de cooperación y coordinación en la ejecución (arts. 15-19).

(9) Conforme a la Ley 38/1999, de Ordenación de la Edificación, quienes están habilitados para la redacción de proyectos, dirección y ejecución de obras. 


\section{VI.1. Actuaciones y sujetos obligados}

A) Tipos de actuaciones sobre el medio urbano (art. 7): Son aquéllas que tienen por objeto realizar obras

- de rehabilitación edificatoria: cuando existan situaciones de insuficiencia o degradación de los requisitos básicos de funcionalidad, seguridad y habitabilidad de las edificaciones (10),

- de regeneración y renovación urbanas: cuando afecten, tanto a edificios, como a tejidos urbanos, pudiendo llegar a incluir obras de nueva edificación en sustitución de edificios previamente demolidos. Tendrán carácter integrado cuando articulen medidas sociales, ambientales y económicas enmarcadas en una estrategia administrativa global y unitaria.

B) Sujetos obligados (art. 8):

Con carácter general aquellos a los que la legislación de ordenación territorial y urbanística atribuya dicha obligación y, además, los siguientes

a) Los propietarios y los titulares de derechos de uso otorgados por ellos, en la proporción acordada en el correspondiente contrato o negocio jurídico que legitime la ocupación. En ausencia de éste, o cuando el contrato no contenga cláusula alguna relativa a la citada proporción, corresponderá a éstos o a aquéllos, en función de si las obras tienen o no el carácter de reparaciones menores motivadas por el uso diario de la vivienda, sus instalaciones y servicios. La determinación se realizará de acuerdo con la normativa reguladora de la relación contractual y, en su caso, con las proporciones que figuren en el Registro de la Propiedad, relativas al bien y a sus elementos anexos de uso privativo.

b) Las comunidades de propietarios y, en su caso, las agrupaciones de comunidades de propietarios, así como las cooperativas de viviendas, con respecto a los elementos comunes de la construcción, el edificio o complejo inmobiliario en régimen de propiedad horizontal y de los condominios, sin perjuicio del deber de los propietarios de las fincas o elementos separados de uso privativo de contribuir, en los términos de los estatutos de la comunidad o agrupación de comunidades o de la cooperativa, a los gastos en que incurran estas últimas.

c) Las Administraciones Públicas, cuando afecten a elementos propios de la urbanización y no exista el deber legal para los propietarios de asumir su coste, o cuando éstas financien parte de la operación con fondos públicos, en los supuestos de ejecución subsidiaria, a costa de los obligados.

La Ley amplía las facultades reconocidas a las comunidades de vecinos, agrupaciones de propietarios y cooperativas de viviendas, para actuar en el mercado inmobiliario con plena capacidad jurídica para todas las operaciones, incluidas las crediticias, relacionadas con el cumplimiento del deber legal de conservación, e introduce los instrumentos de gestión y los mecanismos de cooperación interadministrativa que tienen por objeto fortalecer el marco en el que las citadas actuaciones se desenvuelven.

(10) El artículo 3 de la Ley 38/1999, de Ordenación de la Edificación, sobre las condiciones de habitabilidad, 


\section{VI.2. Ordenación y gestión}

A) La iniciativa en la ordenación de las actuaciones de rehabilitación edificatoria, regeneración y renovación urbanas (art. 9.1) corresponde a

- Las Administraciones Públicas, las entidades públicas adscritas o dependientes de las mismas, en las condiciones que se detallan seguidamente.

- Los propietarios de terrenos, construcciones, edificaciones y fincas urbanas, los titulares de derechos reales o de aprovechamiento.

- Las comunidades y agrupaciones de comunidades de propietarios, las cooperativas de viviendas constituidas al efecto.

- Las empresas, entidades o sociedades que intervengan en nombre de cualesquiera de los sujetos anteriores (11).

En el caso de las Administraciones Públicas (art. 9.2):

- Adoptarán medidas que aseguren la realización de las obras de conservación, y la ejecución de actuaciones de rehabilitación edificatoria, de regeneración y renovación urbanas que sean precisas.

- Formularán y ejecutarán los instrumentos que las establezcan, cuando existan situaciones de insuficiencia o degradación de los requisitos básicos de funcionalidad, seguridad y habitabilidad de las edificaciones; obsolescencia o vulnerabilidad de barrios, de ámbitos, o de conjuntos urbanos homogéneos; o situaciones graves de pobreza energética.

- Serán prioritarias, en tales casos, las medidas que procedan para eliminar situaciones de infravivienda, para garantizar la seguridad, salubridad, habitabilidad y accesibilidad universal y un uso racional de la energía, así como aquellas que, con tales objetivos, partan bien de la iniciativa de los propios particulares incluidos en el ámbito, bien de una amplia participación de los mismos en ella.

B) Reglas básicas para la ordenación y ejecución de las actuaciones (art. 10):

- Si hay necesidad de alterar la ordenación urbanística vigente, se observarán los trámites procedimentales requeridos por la legislación aplicable para realizar la correspondiente modificación, la cual podrá prever la aprobación simultánea (art. 10.1.1.\%). Se acompañará el informe o memoria de sostenibilidad económica del artículo 11.

- Si lo anterior no es preciso, se hará una delimitación y aprobación de un ámbito de actuación conjunta, o la identificación de la actuación aislada que corresponda, a propuesta de los sujetos obligados y a elección del Ayuntamiento (art. 10.1.2. ${ }^{\circ}$.

- El acuerdo administrativo que delimite los ámbitos de actuación o autorice las actuaciones aisladas garantizará, en todo caso, la realización de las notificaciones requeridas, el trámite de información al público cuando éste sea preceptivo.

(11) Como prevé el art. $13.3 .1^{\circ}$, en las actuaciones por iniciativa pública podrán presentar ofertas en los concursos "cualesquiera personas físicas o jurídicas, interesadas en asumir la gestión», incluso los propietarios constituidos en asociación administrativa. 
- Un avance de la equidistribución que sea precisa, entre todos los afectados, de los costes derivados de la ejecución de la correspondiente actuación y de los beneficios imputables a la misma, incluyendo entre ellos las ayudas públicas y todos los que permitan generar algún tipo de ingreso vinculado a la operación (12)

- El plan de realojo temporal y definitivo, y de retorno a que dé lugar, en su caso (artículo 10.2) (13).

- Se prevé la posibilidad de ocupar las superficies de espacios libres o de dominio público que resulten indispensables que detalla (art. 10.3).

- También la de otros espacios sobre los que se deban realizar obras para reducir al menos, en un 30 \% la demanda energética anual de calefacción o refrigeración del edificio (art. 10. 4).

- Cuando afecten a inmuebles declarados de interés cultural o sujetos a régimen de protección, se buscarán soluciones innovadoras que serán informadas favorablemente por el órgano competente (art. 10.5).

C) Memoria de viabilidad económica (art. 11):

Con carácter previo a las actuaciones de ordenación y ejecución se precisa elaborar una memoria que asegure su viabilidad, la rentabilidad, la adecuación a los límites del deber legal de conservación y del equilibrio entre beneficios y cargas con los elementos y determinaciones que establece.

De entre ellos se ha de destacar que, en primer lugar, se refiere al estudio comparado de los parámetros urbanísticos existentes y, en su caso, de los propuestos, con identificación de las determinaciones urbanísticas básicas referidas a edificabilidad, usos y tipologías edificatorias y redes públicas que habría que modificar. De modo que se podrán ponderar «las modificaciones sobre incremento de edificabilidad o densidad, o introducción de nuevos usos, así como la posible utilización del suelo, vuelo y subsuelo de forma diferenciada, para lograr un mayor acercamiento al equilibrio económico, a la rentabilidad de la operación y a la no superación de los límites del deber legal de conservación» (14).

(12) La equidistribución tomará como base las cuotas de participación que correspondan a cada uno de los propietarios en la comunidad de propietarios o en la agrupación de comunidades de propietarios, en las cooperativas de viviendas que pudieran constituirse al efecto, así como la participación que, en su caso, correspon$\mathrm{da}$, de conformidad con el acuerdo al que se haya llegado, a las empresas, entidades o sociedades que vayan a intervenir en la operación, para retribuir su actuación.

(13) La DF 12. ${ }^{\text {a }}$ modifica el art. 16 TRLS, que garantiza, como uno de los "deberes vinculados a la promoción de las actuaciones de transformación urbanística y a las actuaciones edificatorias", "el realojamiento de los ocupantes legales que se precise desalojar de inmuebles situados dentro del área de actuación y que constituyan su residencia habitual, así como el retorno cuando tenga derecho a él, en los términos establecidos en la legislación vigente».

(14) Constituyen medidas de flexibilidad normativa para lograr la viabilidad económica de estas complejas y costosas operaciones de rehabilitación, regeneración y renovación urbanas, que alcanzan a la reducción de las cesiones de suelo, recuperación mayor de plusvalía por el aumento de la densidad y la edificabilidad. En este mismo sentido se ha de contemplar la previsión por la Disposición Transitoria Segunda de la posibilidad de que las Comunidades Autónomas dejen temporalmente en suspenso el cumplimiento del artículo 10.1.b) TRLS, sobre previsión de un $30 \%$ del suelo con destino a uso residencial de protección, siempre que exista un porcentaje de viviendas protegidas construida y sin vender superior al $15 \%$ de las previstas o resultantes del planeamiento vigente y una evidente desproporción entre la reserva legalmente exigible y la demanda real; que los instrumentos de ordenación no hayan sido aprobados definitivamente antes de la entrada en vigor de esta Ley o que, si lo hubiese sido, no cuenten con la aprobación definitiva del proyecto o proyectos de equidistribución. 
El análisis de la inversión ponderará la capacidad de generar ingresos suficientes para financiar la mayor parte del coste de la transformación física propuesta, garantizando el menor impacto posible en el patrimonio personal de los particulares, medido en cualquier caso, dentro de los límites del deber legal de conservación. Se considerará para integrarse en la gestión, mediante la financiación de parte de la misma, o de la red de infraestructuras o de la operación por medio de ahorros amortizables en el tiempo.

D) Efectos de la delimitación de los ámbitos de gestión y ejecución de las actuaciones (art. 12):

a) Comporta la declaración de la utilidad pública o, en su caso, el interés social, cara a expropiaciones, venta y sustitución forzosas de los bienes y derechos, y su sujeción a los derechos de tanteo y retracto a favor de la Administración actuante.

b) Legitima la ocupación de las superficies de espacios libres o de dominio público de titularidad municipal que sean indispensables para la instalación de ascensores u otros elementos para garantizar la accesibilidad universal, siendo la aprobación definitiva causa suficiente para que se establezca una cesión de uso del vuelo por el tiempo en que se mantenga la edificación o, en su caso, su recalificación y desafectación, con enajenación posterior a la comunidad o agrupación de comunidades de propietarios correspondiente, siempre que resulte inviable técnica o económicamente cualquier otra solución y quede garantizada la funcionalidad del dominio público correspondiente. Si fuere preciso ocupar bienes de dominio público pertenecientes a otras Administraciones, los Ayuntamientos podrán solicitar a su titular la cesión de uso o desafectación de los mismos.

c) La aprobación definitiva es causa suficiente para que se establezca una cesión de uso del vuelo por el tiempo en que se mantenga la edificación o, en su caso, su recalificación y desafectación, con enajenación posterior a la comunidad de propietarios correspondiente, siempre que resulte inviable técnica o económicamente cualquier otra solución y quede garantizada la funcionalidad del dominio público correspondiente.

d) Marca el inicio de las actuaciones a realizar, de conformidad con la forma de gestión por la que haya optado la Administración actuante.

E) Formas de ejecución (art. 13):

Las Administraciones Públicas podrán utilizar todas las modalidades de gestión directa e indirecta admitidas por la legislación de régimen jurídico, de contratación de las Administraciones Públicas, de régimen local y de ordenación territorial y urbanística, conforme a las siguientes reglas:

a) En la expropiación, no será preciso el consentimiento del propietario para pagar el correspondiente justiprecio expropiatorio en especie, cuando el mismo se efectúe dentro del propio ámbito de gestión y dentro del plazo temporal establecido para la terminación de las obras correspondientes. La liberación de la expropiación no tendrá carácter excepcional, y podrá ser acordada discrecionalmente por la Administración actuante, cuando se aporten garantías suficientes sobre el cumplimiento de sus obligaciones, por parte del propietario liberado. 
b) En la ejecución subsidiaria a cargo de la Administración Pública, ésta sustituirá al titular o titulares del inmueble, asumiendo la facultad de edificar o de rehabilitarlos con cargo a aquéllos.

c) La Administración, en los dos casos anteriores, como cuando la iniciativa fuese pública, podrá optar por ejecutar las obras directamente o por convocar un concurso público. Para poder participar los propietarios, han de constituir previamente una asociación administrativa que se regirá por lo dispuesto en la legislación de ordenación territorial y urbanística, en relación con las Entidades Urbanísticas de Conservación. En el concurso público podrán participar "cualesquiera personas físicas o jurídicas, interesadas en asumir la gestión de la actuación, incluyendo los propietarios que formen parte del correspondiente ámbito" constituidos en asociación administrativa (15). Se establecen las condiciones para la adjudicación dando prioridad a las más ventajosas, salvo en el incumplimiento de la función social de la propiedad o los plazos de ejecución (art. 9.2 LS).

d) Podrán suscribirse convenios de colaboración entre las Administraciones Públicas y las entidades públicas adscritas o dependientes de las mismas, que tengan como objeto, entre otros, conceder la ejecución a un Consorcio previamente creado, o a una sociedad de capital mixto de duración limitada, o por tiempo indefinido, en la que las Administraciones Públicas ostentarán la participación mayoritaria y ejercerán, en todo caso, el control efectivo, o la posición decisiva en su funcionamiento.

F) Derechos de realojamiento y de retorno (art. 14).

En la ejecución de las actuaciones que requieran el desalojo de los ocupantes legales de inmuebles que constituyan su residencia habitual, deberán garantizar el derecho de aquéllos al realojamiento en los términos establecidos por la Ley de Suelo y por la legislación sobre ordenación territorial y urbanística, en las siguientes condiciones:

- Están obligados a realizarlo la Administración expropiante, el beneficiario de la expropiación, o el promotor de la actuación. Se ha de hacer en viviendas sometidas a algún régimen de protección pública y superficie adecuada a sus necesidades, dentro de los límites establecidos por la legislación protectora. La entrega de la vivienda de reemplazo, en el régimen en que se viniera ocupando la expropiada, equivaldrá al abono del justiprecio expropiatorio, salvo que el expropiado opte por percibirlo en metálico, en cuyo caso no tendrá derecho de realojo.

- En las actuaciones aisladas sin expropiación, los arrendatarios tendrán el derecho a un alojamiento provisional, así como a retornar cuando sea posible, siendo ambos derechos ejercitables frente al dueño de la nueva edificación, y por el tiempo que reste hasta la finalización del contrato.

(15) Medida que abre el camino al "agente rehabilitador», al que no se le atribuye el nombre, aunque la variante es la de las "empresas o entidades de rehabilitación», algo más matizado en su contenido pero con el mismo criterio de comprometer al capital privado en el proceso. Esta figura ya ha sido creada por algunas Comunidades Autónomas, como el Decreto 137/2013, de 30 de julio, por el que se aprueba el Plan de Rehabilitación y Vivienda de Extremadura 2013-2016, que configura al Agente Rehabilitador como entidad colaboradora. Ha sido regulado por la Orden de 23 de julio de 2013. 
- El derecho de realojamiento es personal e intransferible, salvo en el caso de los herederos forzosos o del cónyuge supérstite, si era también su residencia habitual.

- Se determinan las reglas mínimas aplicables al procedimiento de realojamiento.

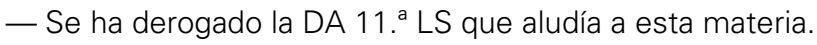

\section{VI.3. Fórmulas de cooperación y coordinación para participar en la ejecución}

A) Facultades de los sujetos legitimados (art. 15).

a) Sujetos (art. 15.1):

Podrán participar en la ejecución de las actuaciones de rehabilitación edificatoria y en las de regeneración y renovación urbanas, además de las Administraciones Públicas competentes, las entidades públicas adscritas o dependientes de las mismas y las comunidades y agrupaciones de comunidades de propietarios, las cooperativas de viviendas y las asociaciones administrativas constituidas al efecto, los propietarios de terrenos, construcciones, edificaciones y fincas urbanas y los titulares de derechos reales o de aprovechamiento, así como las empresas, entidades o sociedades que intervengan por cualquier título en dichas operaciones y las asociaciones administrativas que se constituyan por ellos de acuerdo con lo previsto en la legislación sobre ordenación territorial y urbanística o, en su defecto, por el artículo siguiente.

b) Régimen (art. 15.2).

La participación se producirá, siempre que sea posible, en un régimen de equidistribución de cargas y beneficios.

c) Facultades de los sujetos (art. 15.3):

- Plena capacidad jurídica para todas las operaciones, incluidas las crediticias, relacionadas.

- Constituir asociaciones administrativas para participar en los concursos públicos que la Administración convoque a los efectos de adjudicar la ejecución de las obras correspondientes, como fiduciarias con pleno poder dispositivo sobre los elementos comunes del correspondiente edificio o complejo inmobiliario y las fincas pertenecientes a los propietarios miembros de aquéllas, sin más limitaciones que las establecidas en sus correspondientes estatutos.

- Asumir por sí mismos o en asociación con otros sujetos públicos o privados, intervinientes, la gestión de las obras.

- Constituir un fondo de conservación y de rehabilitación, que se nutrirá con aportaciones específicas de los propietarios a tal fin y con el que podrán cubrirse impagos de las cuotas de contribución a las obras correspondientes.

- Ser beneficiarios de expropiaciones y de las medidas de fomento y de las ayudas otorgadas a los propietarios de las fincas.

- Otorgar escrituras públicas de modificación del régimen de propiedad horizontal, de los elementos comunes como a las fincas de uso privativo, para 
acomodarlas a los resultados de las obras de rehabilitación edificatoria y de regeneración y renovación urbanas en cuya gestión participen o que directamente lleven a cabo.

- Solicitar créditos para obtener financiación para las obras de conservación y para las actuaciones previstas.

B) Asociaciones administrativas (art. 16).

a) Tendrán personalidad jurídica propia y naturaleza administrativa, se regirán por sus estatutos y por lo dispuesto en esta Ley, con independencia de las demás reglas procedimentales específicas que provengan de la legislación de ordenación territorial y urbanística.

b) Dependerán de la Administración urbanística actuante, a quién competerá la aprobación de sus estatutos, a partir de cuyo momento adquirirán la personalidad jurídica.

c) Los acuerdos se adoptarán por mayoría simple de cuotas de participación, salvo que en los estatutos o en otras normas se establezca un quórum especial para determinados supuestos. Podrán impugnarse en alzada ante la Administración urbanística actuante.

d) Su disolución se producirá por el cumplimiento de los fines para los que fueron creadas y requerirá acuerdo de la Administración urbanística actuante, previa constancia del cumplimiento de las obligaciones que queden pendientes.

C) Convenios para la financiación de las actuaciones (art. 17):

Las Administraciones Públicas actuantes, los agentes responsables de la gestión y ejecución de actuaciones de rehabilitación edificatoria y de regeneración y renovación urbanas, y los demás sujetos podrán celebrar entre sí los siguientes contratos:

a) Contrato de cesión, con facultad de arrendamiento u otorgamiento de derecho de explotación a terceros, de fincas urbanas o de elementos de éstas por tiempo determinado a cambio del pago aplazado de la parte del coste que corresponda abonar a los propietarios de las fincas.

b) Contrato de permuta o cesión de terrenos o de parte de la edificación sujeta a rehabilitación por determinada edificación futura.

c) Contrato de arrendamiento o cesión de uso de local, vivienda o cualquier otro elemento de un edificio por plazo determinado a cambio de pago por el arrendatario o cesionario de todos o de alguno de los siguientes conceptos: impuestos, tasas, cuotas a la comunidad o agrupación de comunidades de propietarios o de la cooperativa, gastos de conservación y obras de rehabilitación y regeneración y renovación urbanas.

d) Convenio de explotación conjunta del inmueble o de partes del mismo.

e) A las cooperativas de viviendas, los contratos de cesión y arrendamiento sólo alcanzarán a los locales comerciales y a las instalaciones y edificaciones complementarias de su propiedad.

f) Se derogan los artículos sobre Rehabilitación y Vivienda (107 al 111) de la Ley 2/2011, de 4 de marzo, de Economía Sostenible. 
D) Cooperación interadministrativa (art. 18):

a) Podrán beneficiarse de la colaboración y la cooperación económica de la Administración General del Estado las actuaciones con cobertura en los correspondientes planes estatales que tengan por objeto:

- La conservación, la rehabilitación edificatoria y la regeneración y renovación urbanas y se conciban en los correspondientes Planes estatales.

- Los instrumentos para la ordenación y gestión de las actuaciones que tengan por finalidad actuar sobre ámbitos urbanos degradados, desfavorecidos y vulnerables o que padezcan problemas de naturaleza análoga que combinen variables económicas, ambientales y sociales.

- Las actuaciones que tengan como objeto actuar en ámbitos de gestión aislada o conjunta, con la finalidad de eliminar la infravivienda, garantizar la accesibilidad universal o mejorar la eficiencia energética de los edificios.

b) Las Administraciones Públicas fomentarán de manera conjunta la actividad económica, la sostenibilidad ambiental y la cohesión social y territorial por medio de convenios interadministrativos de asignación de fondos que correspondan.

E) Organización de la cooperación (art. 19):

a) Convenios:

Las Administraciones Públicas que cooperen en la gestión de las actuaciones reguladas por esta Ley podrán acordar mediante convenio con los sujetos legitimados (art. 15):

- La organización de la gestión de la ejecución, que podrá revestir la forma de consorcio o de sociedad mercantil de capital mixto, incluso con participación privada minoritaria.

- El procedimiento y la competencia para la determinación del gestor directamente responsable de la ejecución cuando no la asuma directamente una de las Administraciones actuantes o el consorcio o la sociedad constituidos al efecto.

- Los términos y las condiciones concretas, incluidas las ayudas e incentivos públicos, de la ordenación y la ejecución de la actuación de que se trate, los cuales podrán, a su vez, concretarse mediante acuerdos entre el gestor responsable de la actuación y cualesquiera de los sujetos.

b) Naturaleza:

Los convenios tendrán carácter jurídico-administrativo, correspondiendo a la jurisdicción contencioso-administrativa el conocimiento de cualesquiera cuestiones relacionadas con ellos. 


\section{Disposiciones adicionales}

\section{VII.1. Sistema informativo general}

La DA $1 .^{a}$ establece un sistema informativo general para asegurar la obtención, actualización permanente y explotación de la información necesaria para el desarrollo de las políticas y las acciones a que se refieren los artículos 3, 4 y 5 para un medio urbano sostenible.

La Administración General del Estado, en colaboración con las Comunidades Autónomas y las Administraciones Locales, definirá y promoverá la aplicación de los criterios y principios básicos que posibiliten, desde la coordinación y complementación con las administraciones competentes en la materia, la formación y actualización permanente de un sistema informativo general e integrado, comprensivo, al menos, de los siguientes instrumentos:

a) Censos de construcciones, edificios, viviendas y locales desocupados y de los precisados de mejora o rehabilitación.

b) Mapas de ámbitos urbanos deteriorados, obsoletos, desfavorecidos o en dificultades, precisados de regeneración y renovación urbanas, o de actuaciones de rehabilitación edificatoria.

c) El sistema público general e integrado de información sobre suelo y urbanismo, previsto en la disposición adicional primera del texto refundido de la Ley del Suelo, que tendrá la consideración de información urbanística para el acceso a la misma.

\section{VII.2. Sistema informativo catastral}

Según la DA 2. ${ }^{a}$ lo dispuesto en esta Ley se entiende sin perjuicio de lo previsto en el texto refundido de la Ley del Catastro inmobiliario (RDL 1/2004, de 5 de marzo), en particular en lo que se refiere a la utilización de la referencia catastral, la incorporación de la certificación catastral descriptiva y gráfica y las obligaciones de comunicación, colaboración y suministro de información previstas por la normativa catastral. Conforme a su DF 2. ${ }^{a}$ de aquella, que se deroga.

\section{VII.3. Infracciones y sanciones en materia de certificación de la eficiencia energética de los edificios}

Tipifica las infracciones y las sanciones en las DDAA 3. ${ }^{a}$ y $4 .^{a}$.

Las primeras podrán ser muy graves, graves y leves.

Gradúa las sanciones en función de la tipificación anterior en infracciones leves, multa de 300 a 600 euros; infracciones graves, multa de 601 a 1.000 euros; muy graves, multa de 1.001 a 6.000 euros. Si el beneficio fuese superior a la sanción el importe será el equivalente al beneficio obtenido. 


\section{Disposiciones transitorias}

\section{VIII.1. Calendario para la realización del Informe de Evaluación de los Edificios. (DT 1. ${ }^{\mathrm{a}}$ )}

Con independencia de lo que puedan regular con mayor exigencia las CCAA, se establece la obligación de disponer del Informe de Evaluación como mínimo, en relación con los siguientes edificios y en los plazos que se establecen:

a) Los edificios de tipología residencial de vivienda colectiva con una antigüedad superior a 50 años, en el plazo máximo de cinco años, a contar desde la fecha en que alcancen dicha antigüedad, salvo que ya cuenten con una inspección técnica vigente. Se exigirá el Informe de Evaluación cuando corresponda su primera revisión de acuerdo con aquella normativa, siempre que la misma no supere el plazo de diez años, a contar desde la entrada en vigor de esta Ley.

b) Los edificios cuyos titulares pretendan acogerse a ayudas públicas con el objetivo de acometer obras de conservación, accesibilidad universal o eficiencia energética, con anterioridad a la formalización de la petición de la correspondiente ayuda.

c) El resto de los edificios, cuando así lo determine la normativa autonómica o municipal, que podrá establecer especialidades de aplicación del citado informe, en función de su ubicación, antigüedad, tipología o uso predominante.

d) El informe de la Inspección Técnica de Edificios o instrumento de naturaleza análoga se integrará como parte del informe regulado por la Ley, teniéndose éste último por producido, en todo caso, cuando el ya realizado haya tenido en cuenta exigencias derivadas de la normativa autonómica o local iguales o mayores a las establecidas por esta Ley.

\section{VIII.2. Regla temporal de aplicación excepcional de la reserva mínima de suelo para vivienda protegida (DT 2. ${ }^{\text {a) }}$}

Durante un plazo máximo de cuatro años a contar desde la entrada en vigor de esta Ley, las Comunidades Autónomas podrán dejar en suspenso la aplicación de lo dispuesto en el artículo 10.1 b) del texto refundido de la Ley de Suelo, aprobado por el Real Decreto Legislativo 2/2008, de 20 de junio, determinando el período de suspensión y los instrumentos de ordenación a que afecte, siempre que se cumplan, como mínimo, los siguientes requisitos:

a) Que los citados instrumentos justifiquen la existencia de un porcentaje de vivienda protegida ya construida y sin vender en el Municipio, superior al $15 \%$ de las viviendas protegidas previstas o resultantes del planeamiento vigente $y$ una evidente desproporción entre la reserva legalmente exigible y la demanda real con posibilidad de acceder a dichas viviendas.

b) Que dichos instrumentos de ordenación no hayan sido aprobados definitivamente antes de la entrada en vigor de esta Ley o que, en el caso de haber sido aprobados, no cuenten aún con la aprobación definitiva del proyecto o proyectos de equidistribución necesarios. 


\section{Modificaciones normativas introducidas por las disposiciones finales}

Como se ha recogido al inicio, las 20 disposiciones finales afectan a 16 leyes y un Real Decreto.

\section{IX.1. Modificaciones de mayor relieve}

Se destacan algunas directamente relacionadas con el contenido material de la Ley:

- DF 1. ${ }^{\text {a }}$ afecta a los arts. 2, 3, 9, 10 y 17 de la Ley 49/1960, de 21 de julio, sobre Propiedad Horizontal, en relación con su ámbito, cuotas, obligaciones de los propietarios, realización de obras, autorizaciones administrativas, división de elementos, régimen de mayorías y fondos de reserva. Se trata de dar facilidades para las operaciones de rehabilitación, regeneración y renovación del patrimonio edificado en régimen de propiedad horizontal, incorporando medidas que, hasta ahora, se iban logrando por resoluciones judiciales en aras al interés general de las comunidades de vecinos para la mejora de los servicios. Así, por ejemplo, la modificación de su artículo 10 regula la obligatoriedad, sin acuerdo de la Junta de propietarios, aunque modifique el título o los estatutos, de las obras de rehabilitación, regeneración y renovación urbana.

— La DF 3. ${ }^{a}$ afecta a los arts. 2.2 b), 3.1 y 3.2 de la Ley 38/1999, de 5 de noviembre, de Ordenación de la Edificación, en cuanto al concepto de edificación incluyendo todos los edificios existentes, los requisitos básicos de la edificación y la aplicación del Código Técnico de la Edificación.

- La DF 11. a modifica los artículos 1 y 2 y el anejo III del Código Técnico de la Edificación para resolver los problemas que plantea en relación con la rehabilitación, que en los aspectos técnicos se tratará por Orden Ministerial.

- La DF 14. ${ }^{a}$ alcanza al RD-L 6/2012, de 9 de marzo, de medidas urgentes de protección de deudores hipotecarios sin recursos sobre el ámbito subjetivo, incluyendo a los fiadores, y al beneficio de excusión, incorporando a los avalistas.

- La DF 17. ${ }^{\text {a }}$ se refiere a la Ley $1 / 2013$, de 14 de mayo, de medidas para reforzar la protección a los deudores hipotecarios, reestructuración de deuda y alquiler social, con el objetivo de aportar una mejora técnica, que afecta al Fondo social de viviendas (DA 1.a), a la desaparición del derecho a las plusvalías compartidas, al procedimiento extrajudicial y a las mejoras en el procedimiento de ejecución.

\section{IX.2. La disposición final $12 .^{a}$ y la Ley de Suelo}

De entre todas las modificaciones la más importante, a estos efectos, por su contenido es la DF 12. ${ }^{a}$, respecto a los artículos 2, 5, 6, 8 a 10, 12, 14 a 17, 20, 36, 37, 39, 51 y 53, la DA $3 .^{a}$ y la DF $1 .^{a}$ del texto refundido de la Ley de Suelo-TRLS, aprobado por el Real Decreto Legislativo 2/2008, de 20 de junio, que reciben una nueva redacción. Con base en el epígrafe IX del Preámbulo se realiza una exposición resumida, que exige, en todo caso, acudir a los nuevos textos legales. 
A) Se completa la regulación del deber legal de conservación en los tres niveles que la legislación vigente configura(16):

a) Primer nivel básico o estricto:

- El deber de conservación conlleva, con carácter general, el destino a usos compatibles con la ordenación territorial y urbanística y la necesidad de garantizar la seguridad, salubridad, accesibilidad y ornato legalmente exigibles (art. 9 LS), además de garantizar la accesibilidad universal a cumplir el año 2015.

- El deber legal de conservación también contiene la necesidad de satisfacer los requisitos básicos de la edificación, establecidos en el artículo 3.1 de la Ley 38/1999, de 5 de noviembre, de Ordenación de la Edificación, sin que el cumplimiento de estos requisitos signifique, con carácter general, la aplicación retroactiva del Código Técnico de la Edificación, aprobado por el Real Decreto 314/2006, de 17 de marzo, a la edificación construida con anterioridad a la entrada en vigor del mismo.

b) Un segundo nivel, en el que el deber de conservación incluye los trabajos y obras necesarios para adaptar y actualizar progresivamente las edificaciones, en particular las instalaciones, a las normas legales que les vayan siendo explícitamente exigibles en cada momento. No se trata de aplicar con carácter retroactivo la normativa, sino de incluir en este deber las obligaciones que para la edificación existente explícitamente vaya introduciendo la normativa del sector con el objetivo de mantener sus condiciones de uso, de acuerdo con la evolución de las necesidades sociales.

c) Tercer nivel, que define con mayor precisión y se perfila más específicamente, el carácter de las obras adicionales incluidas dentro del propio deber de conservación (art. 9 LS), por motivos de interés general, desarrollando lo que la Ley de Suelo definió como "mejora» en dos supuestos que introdujo la Ley 2/2011, de 4 de marzo, de Economía Sostenible: motivos turísticos o culturales y mejora para la calidad y sostenibilidad del medio urbano. En ambos por

- La adecuación parcial, o completa, a todas o a alguna de las exigencias básicas establecidas en el ya citado Código Técnico de la Edificación.

- La imposición del deber requerirá que la Administración, de manera motivada, determine el nivel de calidad que deba alcanzar el edificio.

B) Eliminar las cargas urbanísticas injustificadas sobre los suelos ya urbanizados, que están establecidas con una práctica identidad entre los suelos en situación de urbanizados y los suelos en situación rural, con destino a una operación de transformación urbanística:

- Se completa la escueta regulación contenida respecto del suelo en situación de urbanizado, por el artículo 12.2, con el objeto de permitir su utilización

(16) La DF 12. ${ }^{a}$ modifica el artículo 9.1 TRLS respecto a los deberes y cargas de la propiedad del suelo, añade a las habituales de seguridad, salubridad, ornato, mejora y rehabilitación las "obras adicionales por motivos turísticos y culturales, o para la mejora de la calidad o sostenibilidad del medio urbano", con el límite de la "mitad del valor actual de construcción de un inmueble de nueva planta», en las restantes condiciones que establece respecto a la participación de la Administración en los costes superiores de hasta el 75 \%. 
instrumental al servicio del estatuto jurídico básico de la propiedad del suelo y del régimen de valoraciones e indemnizaciones.

- Se pretende también limitar, a aquellos efectos, la posible consideración como suelos en situación de urbanizados de determinados suelos que, incluso al amparo del planeamiento urbanístico, y sobre la base de su clasificación como suelos urbanos en su categoría de no consolidados, en absoluto la tienen, tanto de conformidad con la definición estatal, como con la propia regulación autonómica.

- Esta modificación se complementa con la derogación del artículo 2 del Reglamento de valoraciones, aprobado por el Real Decreto 1492/2011, de 24 de octubre, que se considera incompatible con la modificación legal.

C) Modificación de las actuaciones de transformación urbanística, para adecuar sus actuales parámetros a la realidad del medio urbano y de las actuaciones que se producen sobre el patrimonio edificado y sobre los propios tejidos urbanos de dotación y las denominadas "actuaciones edificatorias", que engloban:

a) Las de nueva edificación y de sustitución de la edificación existente, como las de rehabilitación edificatoria en la misma, sus instalaciones y espacios comunes, en los términos dispuestos por la Ley 38/1999, de 5 de noviembre, de Ordenación de la Edificación, cuando no concurran los elementos que configuran la esencia de las actuaciones de transformación urbanística.

b) La urbanización, la reforma o renovación de ésta y los reajustes entre nuevas dotaciones y los incrementos de edificabilidad o densidad, los cambios de uso y la utilización del suelo, vuelo y subsuelo de forma diferenciada (17). Entre estas medidas de flexibilidad se establece la posibilidad de que las Comunidades Autónomas dejen temporalmente en suspenso el cumplimiento del artículo 10.1.b) TRLS, sobre previsión de un $30 \%$ del suelo con destino a uso residencial de protección, siempre que exista

- un porcentaje de viviendas protegidas construida y sin vender superior al $15 \%$ de las previstas o resultantes del planeamiento vigente y

- una evidente desproporción entre la reserva legalmente exigible y la demanda real;

- que los instrumentos de ordenación no hayan sido aprobados definitivamente antes de la entrada en vigor de esta Ley o que, si lo hubiese sido, no cuenten con la aprobación definitiva del proyecto o proyectos de equidistribución.

c) Los deberes urbanísticos establecidos por el artículo 16 LS.

Se incorpora en la documentación de los instrumentos de planificación de dichas intervenciones, una memoria de sostenibilidad económica cuyo

(17) Estas medidas de flexibilidad se han de relacionar con la Disposición Transitoria Segunda respecto a la posibilidad de que las Comunidades Autónomas dejen temporalmente en suspenso el cumplimiento del artículo 10.1.b) TRLS, sobre previsión de un $30 \%$ del suelo con destino a uso residencial de protección, siempre que exista un porcentaje de viviendas protegidas construida y sin vender superior al $15 \%$ de las previstas o resultantes del planeamiento vigente y una evidente desproporción entre la reserva legalmente exigible y la demanda real; que los instrumentos de ordenación no hayan sido aprobados definitivamente antes de la entrada en vigor de esta Ley o que, si lo hubiese sido, no cuenten con la aprobación definitiva del proyecto o proyectos de equidistribución. 
objeto será asegurar, con carácter previo a la ejecución de las mismas, que se produce un adecuado equilibrio entre los beneficios y las cargas.

D) Modificación de la previsión básica del 30 \% de la edificabilidad residencial para viviendas de protección oficial en los suelos que fuesen objeto de actuaciones de urbanización.

La estableció con carácter básico la Ley 8/2007, posibilitando una cuantía mayor por la legislación urbanística autonómica, como ha ocurrido generalmente, que se aplicaba por igual a los suelos urbanos y a los suelos urbanizables.

Se flexibiliza cuando la actuación se realiza sobre suelo en situación de urbanizado, con la idea de asegurar en la mayor medida posible la ya complicada viabilidad de las operaciones de renovación urbana que impliquen una reurbanización del ámbito de actuación.

E) Actuaciones sobre zonas muy degradadas de las ciudades, o con un porcentaje de infravivienda muy elevado.

La inexistencia de suelos disponibles en su entorno inmediato para dotar de coherencia a los deberes de entrega de suelo, o para el cumplimiento de determinadas cargas, podrían frustrar su finalidad prioritaria, que es superar tales situaciones. En tales casos, la regla excepcional se justifica por la necesidad de priorizar entre los diversos intereses públicos en presencia.

F) Conforme a los citados principios, se introducen modificaciones del articulado de la Ley de Suelo en su texto refundido:

a) Artículo 2 sobre el Principio de desarrollo territorial y urbano sostenible, que ha de inspirar todas las políticas:

- Se introducen dos nuevas finalidades:

- La prevención adecuada de riesgos y peligros para la seguridad y la salud públicas y la eliminación efectiva de las perturbaciones de ambas.

- La prevención y minimización, en la mayor medida posible, de la contaminación del aire, el agua, el suelo y el subsuelo.

- Se incorpora un apartado 3, que sustituye al 2.c) anterior, incorporando nuevos objetivos sobre el medio urbano: movilidad en coste y tiempo razonable, accesibilidad universal, uso eficiente de recursos y energía, prevención o minimización de impactos negativos de los residuos y contaminación acústica.

b) Artículo 5 sobre los deberes del ciudadano en general en su respeto al medio:

- Respetar y contribuir a preservar el paisaje urbano y el patrimonio arquitectónico y cultural absteniéndose en todo caso de realizar cualquier acto o desarrollar cualquier actividad no permitidos.

c) Artículo 6 sobre la iniciativa pública y privada en las actuaciones de transformación urbanística y de las edificaciones. Destacan aspectos como

- la dirección del proceso por la Administración tanto en los supuestos de iniciativa pública como privada; 
- la iniciativa de los propietarios de transformación urbanística podrá redactar y presentar los instrumentos de ordenación y gestión;

- prohibición del incremento convencional de las obligaciones legales.

d) Artículo 8, sobre las facultades del derecho de propiedad del suelo.

El nuevo texto integra el anterior artículo 13 que se deroga. Se concretan las del propietario del suelo rural para transformarlo en urbanizado conforme al planeamiento, y las facultades del propietario del suelo en situación de urbanizado.

e) Artículo 9, sobre los deberes y cargas del derecho de propiedad del suelo. Se han sistematizado incorporando mayores exigencias.

- Al deber genérico de conservar los terrenos para un uso compatible, la seguridad, salubridad, accesibilidad universal y ornato exigible, se añaden las "obras adicionales por motivos turísticos o culturales» y la «mejora de la sostenibilidad del medio urbano" (Ley 2/2011, de 4 de marzo, de Economía Sostenible). Se limita el importe de la carga a la mitad del valor actual de la construcción de un inmueble de nueva planta (18).

- Para los edificios se añade el deber de realizar los trabajos y obras para cumplir los requisitos del art. 3.1 de la Ley 38/1999, de 5 de noviembre, de Ordenación de la Edificación, y para adaptarlas y actualizar sus instalaciones a las normas exigibles.

- Imposición de la realización de obras para el cumplimiento del deber legal de conservación, con afección real directa e inmediata inscribible como nota marginal en el Registro de la Propiedad, que recogerá su evolución por medio de certificado administrativo. Su incumplimiento da lugar a la ejecución subsidiaria u otras formas de reacción administrativa, con el límite máximo del 75 \% del coste de reposición de la construcción o edificio correspondiente.

- Deber de edificar en el suelo urbanizado en los plazos y completar la urbanización para hacerlo.

- Necesidad de autorización para la edificación. Establecimiento, en relación con el artículo 23 del Real Decreto-Ley 8/2011, de 1 de julio, del régimen del silencio negativo de la aprobación o autorización administrativa para los movimientos de tierras, obras de edificación e instalaciones de nueva planta, ubicación de casas prefabricadas y talas de masas de arbolado. La denegación deberá ser motivada y no podrán adquirirse por silencio administrativo facultades o derechos contrarios a la ordenación territorial o urbanística.

- Sobre la primera ocupación o utilización de edificaciones, si no se cumplen los requisitos, la Administración deberá adoptar las medidas para el cese de la ocupación o utilización comunicada, siendo responsable de los perjuicios a terceros de buena fe si no adopta las medidas en seis meses.

- Prohibición de parcelaciones urbanísticas en suelo en situación rural, sin divisiones, segregaciones o fraccionamientos contrarios a la legislación agraria, forestal o similar.

(18) Conforme al concepto de "coste de reposición» del art. 2.3 de la Ley 8/2013. 
f) Artículo 10.1.b), sobre criterios básicos de utilización del suelo.

Se ha de destacar la previsión de la reserva del $30 \%$ del suelo residencial a vivienda protegida y el $10 \%$ a las actuaciones de reforma o renovación urbana para el suelo urbanizado. Sin embargo se flexibiliza por medio de la legislación urbanística que las puede reducir o eximir cuando los instrumentos de ordenación prevean su cumplimiento en su ámbito territorial de aplicación.

En la Disposición Transitoria 2. ${ }^{a}$ se establece una regla temporal sobre la aplicación excepcional de la reserva mínima de suelo para vivienda protegida durante un plazo máximo de cuatro años, en las condiciones que se han expuesto.

g) Artículo 12, se modifica el apartado 3 y se añade un apartado 4, sobre las situaciones básicas del suelo.

Cambia la definición del suelo urbanizado (19), exigiendo que concurran:

- Estar legalmente integrado en una malla urbana conformada por una red de viales, dotaciones y parcelas propia del núcleo o asentamiento de población del que forme parte,

- Cumplimentar alguna de estas condiciones: Haber sido urbanizado en ejecución de la correspondiente ordenación; tener instaladas y operativas las instalaciones en las condiciones que establece; estar ocupado por la edificación, en el porcentaje de espacios aptos, conforme a la legislación y ordenación (anterior suelo consolidado por la edificación).

h) Artículo 14, sobre actuaciones de transformación urbanística y actuaciones edificatorias.

i) Artículo 15, apartado 4, sobre el informe de sostenibilidad económica.

Se incluirá entre la documentación de los instrumentos de ordenación para las actuaciones de nueva urbanización, reforma o renovación de la urbanización y de las dotaciones, ponderando el impacto de la actuación en las Haciendas Públicas afectadas por la implantación y el mantenimiento de las infraestructuras necesarias o la puesta en marcha y prestación de los servicios resultantes, la suficiencia y adecuación del suelo destinado a usos productivos.

j) Artículo 16, sobre deberes vinculados a la promoción de las actuaciones de transformación urbanística y a las actuaciones edificatorias.

Se diferencian los deberes según se trate de actuaciones de urbanización, de dotación, edificatorias o en núcleos rurales:

- Actuaciones de urbanización (art. 13.1.a): Entregar a la Administración competente:

- El suelo reservado para viales, espacios libres, zonas verdes y restantes dotaciones públicas incluidas en la propia actuación o adscritas a ella para su obtención.

- Los terrenos que el instrumento de ordenación adscriba a la dotación pública de viviendas sometidas a algún régimen de protección, con

(19) Por el cambio del concepto se deroga el artículo 2 del Real Decreto 1492/2011, de 14 de febrero, Reglamento de Valoraciones de la Ley de Suelo. 
destino exclusivo al alquiler, por la legislación aplicable o cuando de la memoria del correspondiente instrumento se derive la necesidad de contar con este tipo de viviendas de naturaleza rotatoria, y cuya finalidad sea atender necesidades temporales de colectivos con especiales dificultades de acceso a la vivienda.

- Con destino a patrimonio público de suelo, el suelo libre de cargas de urbanización correspondiente al porcentaje de la edificabilidad media ponderada de la actuación, o del ámbito superior de referencia en que ésta se incluya, que fije la legislación reguladora de la ordenación territorial y urbanística. Con carácter general, el porcentaje no podrá ser inferior al 5 \% ni superior al $15 \%$. La legislación sobre ordenación territorial y urbanística podrá permitir excepcionalmente reducir o incrementar este porcentaje de forma proporcionada y motivada, hasta alcanzar un máximo del $20 \%$ en el caso de su incremento, para las actuaciones o los ámbitos en los que el valor de las parcelas resultantes sea sensiblemente inferior o superior. La legislación podrá prever su sustitución por otras formas de cumplimiento del deber, excepto cuando pueda hacerse con suelo destinado a vivienda de protección.

- Costear la urbanización y reintegro por las empresas suministradoras de los gastos de instalación.

- Entrega del suelo y obras de infraestructura para el dominio público.

- Garantizar el realojamiento y retorno de los ocupantes de áreas de actuación de regeneración o renovación urbanas.

- Indemnizar a los titulares de derechos sobre las construcciones y edificaciones que deban demolerse, y las obras, instalaciones, plantaciones y sembrados que no puedan conservarse.

- Actuaciones de dotación (art. 14.1.b): Salvedades respecto a los deberes anteriores:

- El deber de entregar a la Administración competente el suelo libre de cargas de urbanización correspondiente al porcentaje de la edificabilidad media ponderada de la actuación o del ámbito superior de referencia en que ésta se incluya, que fije la legislación reguladora de la ordenación territorial y urbanística, se determinará atendiendo sólo al incremento de la edificabilidad media ponderada que, en su caso, resulte de la modificación del instrumento de ordenación. Dicho deber podrá cumplirse mediante la sustitución de la entrega de suelo por su valor en metálico, con la finalidad de costear la parte de financiación pública que pudiera estar prevista en la propia actuación, o a integrarse en el patrimonio público de suelo, con destino preferente a actuaciones de rehabilitación o de regeneración y renovación urbanas.

- El deber de entregar a la Administración competente el suelo para dotaciones públicas relacionado con el reajuste de su proporción, podrá sustituirse, en caso de imposibilidad física de materializarlo en el ámbito correspondiente, por la entrega de superficie edificada o edificabilidad no lucrativa, en un complejo inmobiliario, situado dentro del mismo, tal y 
como prevé el artículo 17.4, o por otras formas de cumplimiento del deber en los casos y condiciones en que así lo prevea la legislación sobre ordenación territorial y urbanística.

- Actuaciones edificatorias:

En relación con las actuaciones edificatorias serán exigibles, de conformidad con su naturaleza y alcance, los deberes referidos en las letras e) y f) del apartado 1 de las actuaciones de urbanización, así como el de completar la urbanización de los terrenos con los requisitos y condiciones establecidos para su edificación.

\section{- Exención:}

Con carácter excepcional y siempre que se justifique adecuadamente que no cabe ninguna otra solución técnica o económicamente viable, los instrumentos de ordenación urbanística podrán

- eximir del cumplimiento de los deberes de nuevas entregas de suelo que les correspondiesen, a actuaciones sobre zonas con un alto grado de degradación e inexistencia material de suelos disponibles en su entorno inmediato.

- Eximir a los aumentos de la densidad o edificabilidad que fueren precisos para sustituir la infravivienda por vivienda que reúna los requisitos legalmente exigibles, con destino al realojamiento y el retorno que exija la correspondiente actuación.

- Núcleos tradicionales legalmente asentados en el medio rural:

Las actuaciones comportarán los deberes legales establecidos, de acuerdo con las características que a éstos atribuya su propia legislación.

- Garantía real y cumplimiento de los deberes:

- Los terrenos incluidos en el ámbito de las actuaciones y los adscritos a ellas están afectados, con carácter de garantía real, al cumplimiento de los deberes de los apartados anteriores.

- Estos deberes se presumen cumplidos con la recepción por la Administración competente de las obras de urbanización o de rehabilitación y regeneración o renovación urbanas correspondientes, o en su defecto, al término del plazo en que debiera haberse producido la recepción desde su solicitud acompañada de certificación expedida por la dirección técnica de las obras, sin perjuicio de las obligaciones que puedan derivarse de la liquidación de las cuentas definitivas de la actuación.

k) Artículo 17, apartados 3, 4 y 6, sobre la formación de fincas y parcelas de los complejos inmobiliarios.

Aconsiderar en cuanto al régimen de los complejos inmobiliarios, su régimen y autorizaciones.

I) Artículo 20, sobre declaración de obra nueva, sus requisitos notariales y registrales.

m) Artículo 36, sobre la procedencia y alcance de la venta o sustitución forzosas.

n) Artículo 37, sobre régimen de venta o sustitución forzosas. 
o) Artículo 39 apartado 1, sobre el destino de los bienes de los patrimonios públicos de suelo.

p) Artículo 51, sobre actos inscribibles en el Registro de la Propiedad.

q) Artículo 53, sobre clases de asientos en el Registro de la Propiedad.

r) Disposición adicional tercera sobre potestades de ordenación urbanística en Ceuta y Melilla.

s) Disposición final primera, apartado 4, letra b), sobre aplicación en Ceuta y Melilla del porcentaje de entrega de suelo del artículo 16.1.b), conforme a la STC 240/2006, de 20 de julio.

\section{Conclusión}

Examinando el contenido de la Ley se comprueba que trata de establecer un nuevo marco normativo tendente a la rehabilitación, regeneración y renovación urbanas con los siguientes fines:

a) La mejora de la calidad de vida del tejido urbano desde la transformación de la acción urbanizadora sobre el espacio exterior para aprovechar el interior de las ciudades, pasando del urbanismo expansivo al concentrado renovado y de mayor calidad residencial y turística.

b) Alcanzar los objetivos comunitarios de eficiencia y ahorro energéticos para contribuir al cumplir las normas comunitarias y los compromisos del Protocolo de Kyoto, en el espacio urbano y las edificaciones.

c) Progresar en la mejora de las condiciones de accesibilidad, servicios y eficiencia del patrimonio edificado.

d) Utilizar la rehabilitación, la regeneración y la renovación para la reconversión del sector inmobiliario urbano antiguo y fomentar la actividad económica en el sector, generar empleos y fomentar el turismo.

Se implementa el derecho comunitario sobre la calidad del medio y la reducción del cambio climático por el certificado de eficiencia energética.

Se introducen en el régimen del suelo y la edificación, a través de importantes modificaciones en el Texto Refundido de la Ley de Suelo, a la que se dota de flexibilidades sobre las exigencias establecidas en los deberes vinculados a aquél, justificadas por el exceso de viviendas construidas, la caída del mercado y los costes de las operaciones de rehabilitación, regeneración y renovación urbanas.

Trabajo recibido el 9 de mayo de 2014.

Aceptado por el Consejo de Redacción el 10 de octubre de 2014. 
LABURPENA: Hiri-birgaikuntzaren, -berroneraketaren eta -berritzearen gaineko erregimen berri bat ezartzen du, hiri-zoruaren iraunkortasunean eta erabileran arreta berezia jarriz, bai eta eraikitako ondarearen kalitatean, irisgarritasunean, zerbitzuetan eta eraginkortasunean ere. Hiri-espazioan eta eraikinetan energia-eraginkortasunari eta -aurrezteari buruzko erkidegoko helburuak lortu nahi ditu erkidegoko arauekin eta Kyotoko Protokoloan jasotako konpromisoekin bat. Horretarako, aldaketa handiak egiten ditu hirigintza-legedian; hiri-zoruko betebeharrak malgutzen ditu, etxebizitza gehiegi dagoelako eraikita, merkatuak behera egin duelako eta hiria birgaitzeko, berroneratzeko eta berritzeko lanek kostu handia dutelako.

HITZ GAKOAK: Hiri-birgaitzea, -berroneratzea eta -berritzea. Hiri-zoruaren erregimena eta iraunkortasuna. Jarduera ekonomikoa sustatzea. Eraikinen ingurumen-kalitatea.

RESUMEN: Establece un nuevo régimen sobre la rehabilitación, regeneración y renovación urbanas, incidiendo en el régimen de la sostenibilidad y uso del suelo urbano, y en la calidad, accesibilidad, servicios y eficiencia del patrimonio edificado. Pretende alcanzar los objetivos comunitarios de eficiencia y ahorro energéticos conforme a las normas comunitarias y los compromisos del Protocolo de Kyoto, en el espacio urbano y las edificaciones. Para ello introduce importantes modificaciones en la legislación urbanística flexibilizando los deberes en suelo urbano, justificándolo en el exceso de viviendas construidas, la caída del mercado y los costes de las operaciones de rehabilitación, regeneración y renovación urbanas.

PALABRAS CLAVE: Rehabilitación, regeneración y renovación urbanas. Régimen y sostenibilidad del suelo urbano. Fomento de la actividad económica. Calidad ambiental de los edificios.

ABSTRACT: A new regime for the urban restoration, regeneration and renovation has been established which affects the regime of sustainability and the use of urban soil and the quality, accesibitlity, services and efficiency of the build patrimony. It purports to accomplish the Community objectives of energetic efficiency and saving according to the Community rules and the Kyoto's agreements within the urban space and buildings. For that purpose it introduces important amendments in the urban legislation by making flexible the duties for the urban soil, justifying it with the surplus of built housing, the decline of the market and the costs of the operations of restoration, regeneration and renovation.

KEYWORDS: Urban restoration, regeneration and renovation. Regime and Sustainability of urban soil. Promotion of the economic activity. Enviromental quality of buildings. 